\title{
A census of the
}

Conrad Aveling and Alexander $\mathrm{H}$. Harcourt

Mountain gorillas exist in the wild today only in the Virunga volcanoes, which span the borders of Zaire, Rwanda and Uganda, and in the Bwindi Forest Reserve of Uganda, and number probably fewer than 400 . The authors describe the 1981 survey of the entire Virunga gorilla population, the first to be done since 1973. The results clearly show how the gorillas in the Rwanda section of the volcanoes have benefited from the protection afforded by the activities of the Karisoke Research Centre and the Mountain Gorilla Project in Rwanda. There is also optimism that the Zaire population, which has retained the potential for increase, could recover if given better protection from poaching and disturbance.

The mountain gorilla Gorilla gorilla beringei, with a wild population of fewer than 400 , is the rarest of the three subspecies of gorilla, and is found only in the $375 \mathrm{sq} \mathrm{km}$ conservation area of the Virunga volcanoes of Zairre, Rwanda and Uganda, and in the $310 \mathrm{sq} \mathrm{km}$ Bwindi Forest Reserve of Uganda. Since the early 1960s, the Bwindi Forest population has probably only decreased slightly (Harcourt, 1981), but the Virunga population roughly halved between 1960 (Schaller, 1963) and the early 1970s (Harcourt and Fossey, 1981). Since 1973 , no census of the whole Virunga population has been conducted in all three countries at the same time, although during that period a trade in gorilla skulls and live infants started, and a major 8

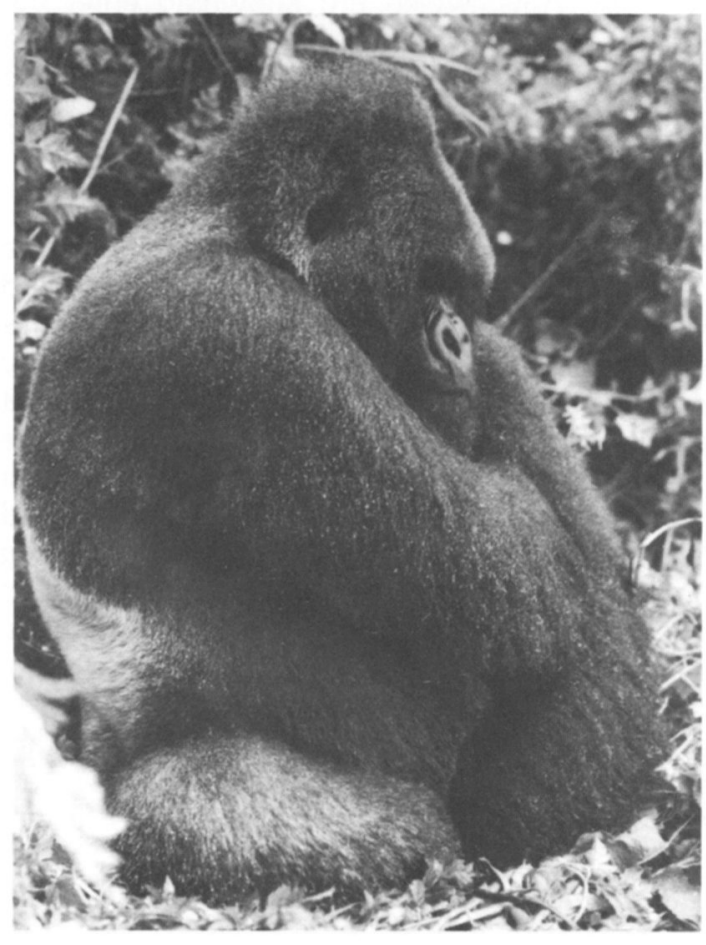

A rain-speckled silverback (C) A.H. Harcourt).

conservation programme-the Mountain Gorilla Project* - was initiated. The census reported here was carried out between May and October 1981 by a team of census workers ${ }^{\dagger}$ in collaboration with the relevant government departments from Rwanda, Zaïre and Uganda.

* The Mountain Gorilla Project (MGP) was launched in 1979 and is sponsored by the Fauna and Flora Preservation Society, Peoples Trust for Endangered Species, African Wildlife Foundation and World Wildlife Fund.

†C. Aveling, G. Campbell, M. Condiotti, A.H. Harcourt, J. Kineman, I. Redmond, and J. Yamagiwa.

Oryx Vol 18 No 1 


\section{Virunga gorillas}

\section{The survey}

The Virunga volcanoes conservation area straddles the borders of three countries, and comprises Zaïre's Parc National de Virunga-Sud (225 sq km), Rwanda's Parc National des Volcans (120 sq km) and Uganda's Gorilla Game Reserve $(30 \mathrm{sq} \mathrm{km})$. The altitudinal range is from 2100 to $4500 \mathrm{~m}$ above sea-level, and the area includes a variety of habitat types, such as bamboo stands, Hagenia/Hypericum forest and giant Senecio and Lobelia. The gorillas live in family groups with overlapping ranges of $5-10 \mathrm{sq}$ $\mathrm{km}$, except for a few solitary males.

The census was made by walking transects through the area until a gorilla trail of up to a week old was found, then following this to the night nest site. Since dung bolus size is correlated with animal age, examination of dung in the nests gives a good indication of the number, and ageclass, of the animals in the group, although dung of infants less than one-year-old is usually missed. Examining three or more consecutive night nest sites provides fairly accurate data on composition of the group. Additional data from the continuously monitored groups of Karisoke Research Centre and the Mountain Gorilla Project were also used but, for consistency, infants of less than one year were omitted from calculations for the whole conservation area.

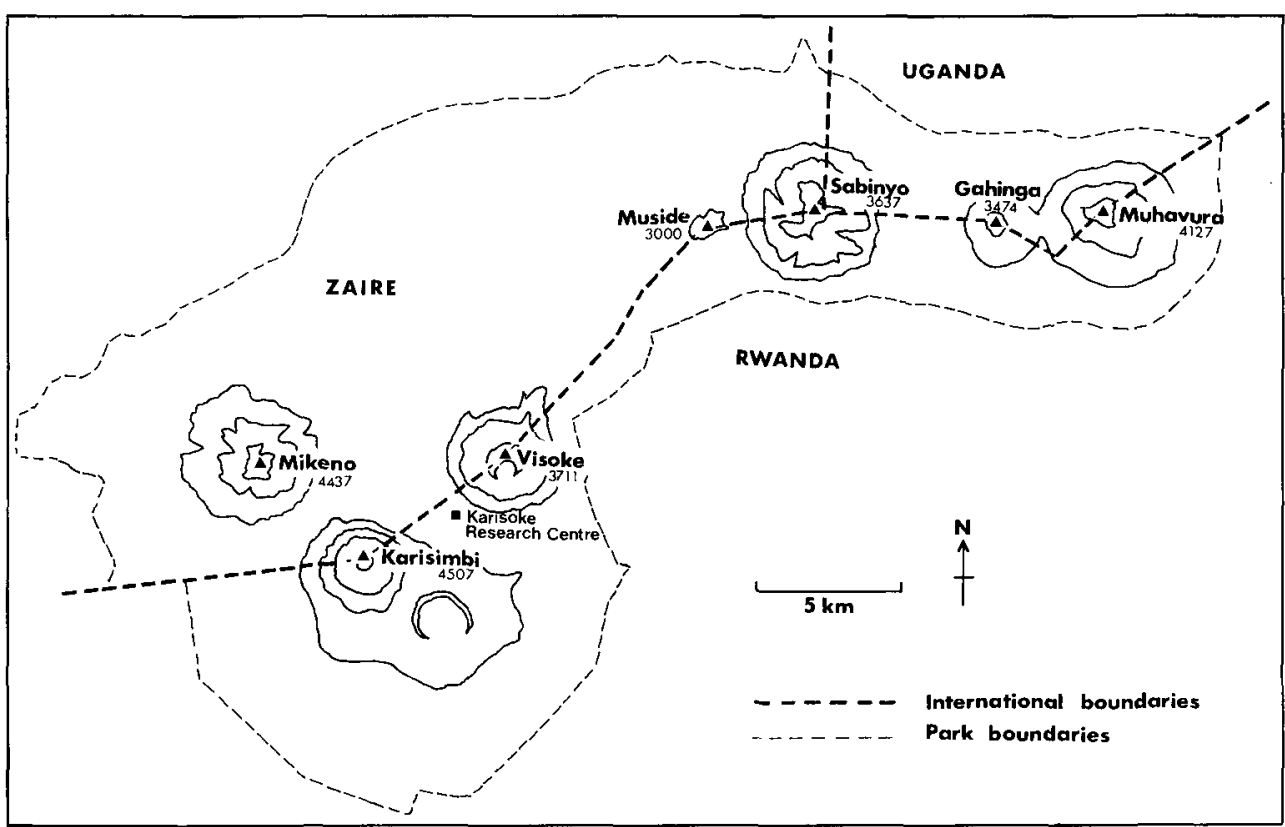

Census of the Virunga gorillas
Map of the Virunga volcanoes, showing international and park boundaries. 
The accuracy of the census method is indicated by the fact that gorilla groups known to exist because of the studies of Karisoke Research Centre, but whose exact whereabouts at the time of the census was unknown, were detected during the census. Four such groups were detected in three separate areas by census workers new to the area, and in two of these areas an additional, previously unknown group was detected. The results are regarded as an almost complete count of the population, at most a 10 per cent underestimate.

In analysing the results, one-kilometre-squares drawn on to a map were considered as having been searched if they contained more than half a kilometre of survey route. All signs of gorillas and recent human activity were noted for each square. The figure for the total percentage of the Virungas searched includes the area monitored by the Karisoke Research Centre and the Mountain Gorilla Project, but this is not included in the comparison of squares containing human and gorilla signs, since the methods of search differed.

The population is divided into the following agesex classes:

$\begin{array}{ll}\text { Silverbacks } & \text { - fully adult males of } 14 / 15 \text { years or more } \\ \text { Blackbacks } & \text { - males of } 8 / 9 \text { years to } 14 / 15 \text { years } \\ \text { Adult females } & \text { - more than } 8 / 9 \text { years } \\ \text { Subadults } & -6 \text { to } 8 / 9 \text { years } \\ \text { Juveniles } & -3 \text { to } 6 \text { years } \\ \text { Infants } & -0 \text { to } 3 \text { years }\end{array}$

Since adult females and young adult males (blackbacks) have the same size of dung bolus, they cannot be distinguished in the census unless the female has a dependent young sharing her nest. From their ratio in known groups, the 'adults of unknown sex' in the census are divided in the ratio of one blackback to two adult females with no dependent young.

Results are compared with previous censuses in the early 1970s (Harcourt et al., 1981), and between 1976 and 1978 (Weber and Vedder, 1983). The population in the early 1970s was regarded as stable, and the approximately eight years between then and the 1981 census reported here, is the equivalent of one generation. Changes in the populations in Zaire and Rwanda during this time are also compared. As no group uses the Ugandan sector exclusively it is ignored. Comparison between Zaire and Rwanda 10 is possible as more than 93 per cent of the groups spend almost all their time in one of the two countries.

\section{Census results}

A total of 242 gorillas was counted, giving an estimated population size of between 242 and 266 , assuming a possible 10 per cent undercount. The 'early 1970s' census estimated between 260 and 290 , and the 1978 census between 252 and 285.

In the Virungas as a whole, there has been a slight decrease in the number of groups (31-28), with a slight increase in the mean group size $(7 \cdot 9-8 \cdot 5)$ since the early 1970s; between 1978 and 1981 however, there has been almost no change in these parameters (in 1978, according to Weber and Vedder, there were 28 groups, with a mean group size of $8 \cdot 8$ ). When Zaire and Rwanda are considered separately, however, the changes are found to have occurred in opposite directions; Zaire shows an increase in number and decrease in group size (14-16, 9.7-7.4), while Rwanda shows a decrease in number and increase in group size (14-10, 6.9-9.7).

The change in Rwanda is statistically significant and seems to be accounted for by a 16 per cent decrease in the number of adults (mainly silverbacks) combined with a 17 per cent increase in the number of immatures. In Zaire, the decrease in mean group size is largely accounted for by a 22 per cent drop in the number of immatures. Adult male numbers declined throughout the Virungas, and 58 per cent of this decline was due to a drop in the numbers of lone males.

In the early 1970 s, there was no significant difference between Zaire and Rwanda in the ratio of adults to immatures (Table 1), but in 1981 the difference was statistically significant. The higher proportion of immatures in Rwanda in 1981,

Table 1. Ratio of adult (Ad) to immature ( $\mathrm{Im}$ ) gorillas in Zaire and Rwanda in the 'early 1970s' and in 1981. Groups sharing Rwanda and Zaire split equally between the countries.

\begin{tabular}{|c|c|c|c|c|c|c|}
\hline & \multicolumn{3}{|c|}{ Zaire } & \multicolumn{3}{|c|}{ Rwanda } \\
\hline & $\% \mathrm{Ad}$ & $\% \operatorname{Im}$ & Total & $\% \mathrm{Ad}$ & $\% \operatorname{Im}$ & Total \\
\hline Early 1970s & 63 & 37 & $146 \cdot 5$ & 64 & 36 & 111.5 \\
\hline 1981 & 67 & 33 & $129 \cdot 5$ & 56 & 44 & $107 \cdot 5$ \\
\hline
\end{tabular}

Oryx Vol 18 No 1 
compared with the early 1970 s, suggests a higher reproduction rate and/or immature survival than in Zaire. The ratio of subadults (born 6-8 years ago) to juveniles and infants (born 1-6 years ago) is significantly different between the two countries, Rwanda's proportion of juveniles and infants (34 per cent) being nearly twice that of Zaire's ( 18.5 per cent).

This difference has appeared despite the fact that there was very little difference between the two countries in the change in size of their breeding populations (Table 2). The decrease in numbers of adult males in Rwanda would not be expected to have an immediate and major effect on breeding success, as it is thought that only one silverback does most of the breeding where there is more than one in a group, although a longer-term effect on immature survival may eventually become evident. In Zaïre, despite a small decrease in numbers of adult females between 1970s and 1981, there are still more than in Rwanda, indicating that the Zaire section of the population retains the capacity to increase.

Table 2. A comparison of the size of the breeding population between Zaire and Rwanda in the 'early 1970s' and 1981. Numbers in parentheses are silverbacks and adult females respectively.

\begin{tabular}{lrcc}
\hline & Virungas & Zaire & Rwanda \\
\hline Early 1970s & $113(31,82)$ & $62(15 \cdot 5,46 \cdot 5)$ & $51(15 \cdot 5,35 \cdot 5)$ \\
1981 & $106(28,78)$ & $58 \cdot 5(17,41 \cdot 5)$ & $47 \cdot 5(11,36 \cdot 5)$ \\
\hline
\end{tabular}

Since the early 1970 s there has been little encroachment of cultivation into the conservation area as a whole, although encroachment into the Ugandan section has been large in proportivi. to its size. As a result of the population decrease, the overall density of the gorilla population has dropped from 0.73 individuals $/ \mathrm{sq} \mathrm{km}$ to 0.68 individuals $/ \mathrm{sq} \mathrm{km}$, but these figures hide an enormous variation in density between different regions of the conservation area. For example, in Rwanda the central sector (which comes under the influence of Karisoke Research Centre and the Mountain Gorilla Project, and is therefore the best protected through constant monitoring) contains four times the density of the eastern sector and eight times that of the southern sector.

Census of the Virunga gorillas

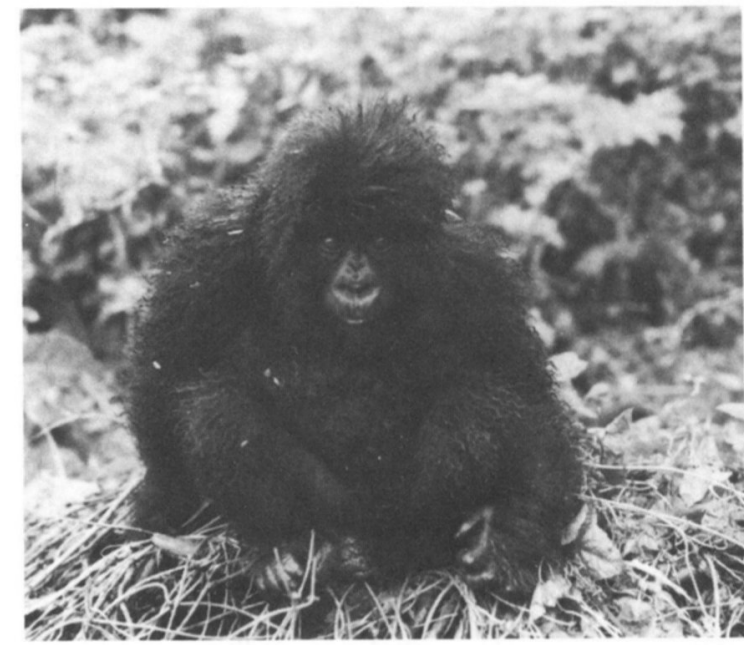

Two-year-old gorilla (C A.H. Harcourt)

It is in fact possible to divide the population of the Virungas into 'guarded' and 'unguarded' groups, and thus illustrate the effect of protection on population composition. The guarded groups are those that are monitored almost daily by Karisoke Research Centre and the Mountain Gorilla Project, and the two groups in Zaire that range close to guard posts. 'Guarded' groups have a significantly higher proportion of immatures than 'unguarded' groups over the Virungas as a whole, and this effect of protection is also seen in each country separately (Table 3).

Table 3. Composition (adult: immature ratio) of 'guarded' (G) and 'unguarded' (UG) groups in 1981. Groups sharing Rwanda and Zaire split equally between the countries.

\begin{tabular}{lcccccc}
\hline & \multicolumn{2}{c}{ Virungas } & & Zaire & \multicolumn{2}{c}{ Rwanda } \\
& G & UG & G & UG & G & UG \\
\hline Adult (per cent) & 51.5 & 67 & 57 & 70 & 49 & 61 \\
Immature (per cent) & 48.5 & 33 & 43 & 30 & 51 & 39 \\
Total & 103 & 135 & 30 & 89 & 73 & 46 \\
\hline
\end{tabular}

The extent of illegal use of the conservation area is also highlighted by the census. Of the onekilometre-squares searched during the survey 51.2 per cent contained evidence of recent $(<2$ weeks) human use, 29.6 per cent contained 
snares, while only 20.4 per cent contained recent gorilla signs. The worst area from this point of view is the Visoke-Mikeno saddle in Zaire, where 70.2 per cent of the squares searched contained traps, compared with 19.4 per cent for the rest of Zaire. Karisimbi, particularly the southern flank, is also heavily used by poachers; 30.1 per cent of the squares searched contained snares, despite the fact that most of the poaching in this area is with dogs.

\section{Conservation implications}

The 1981 census has indicated the possibility of a decline in the Virunga gorilla population, from about 275 in the early 1970 s to about 255 in 1981. In view of the amount of illegal activity in the conservation area, it is perhaps encouraging that the apparent decline was not greater; in fact, within the limits of accuracy of both censuses, the population has remained relatively stable in terms of absolute numbers. Particularly relevant to conservation management, however, are the differences seen in population composition between the sections of the Virungas in Zaire and Rwanda. Despite the fact that 58 per cent of the decline in numbers is accounted for by adult males, the size of the breeding population in each country is remarkably unaffected; however, a 22 per cent drop in the number of immatures in Zaire contrasts strongly with a 17 per cent increase in Rwanda. Clearly the Rwandan gorilla population has benefited from the better protection afforded by the activities of Karisoke Research Centre and the Mountain Gorilla Project; also from the fact that the large number of cattle that used to occupy the Rwandan sector were removed in 1976/7. While the greater proportion of immatures in the Rwandan sector (a change that analysis reveals has occurred within the last six or so years) is indicative of a healthy population, the population in Zaire retains the capacity to increase. The proportion of adult females in the Zaire sector has hardly changed, so with better protection, this population should be able to respond fairly rapidly with an increased rate of reproduction and recruitment.

Threats to the gorillas come directly from poaching and indirectly from disturbance caused by illegal users of the conservation area, including poachers, woodcutters, bamboo collectors, water 12 collectors and smugglers. In the mid-1970s a trade developed in gorilla heads and live infants, for sale to expatriates. Direct poaching for either heads or infants involves the killing of adult gorillas, and in addition, captured or orphaned gorilla infants may die soon after the event. Gorillas are also at risk from wire snares set to catch bushbuck and duiker, and this may be a major cause of mortality, particularly of immatures. In the nine monitored groups comprising 88 animals, six have a missing hand or foot, almost certainly as a result of encounters with snares. At least one infant from a monitored group is known to have died following a snare wound, and during two years three other infants or juveniles from monitored groups were caught in snares (but released and their wounds treated). As immatures are so vulnerable to snares, the increase in patrolling and snare-removal in recent years, by Rwandan Park guards equipped and trained by the Mountain Gorilla Project, must be one of the factors influencing immature survival in Rwanda. Conversely the greater abundance of snares in parts of the Zaire section must partly account for the reduction in immatures seen there.

The presence of so many illegal users in the conservation area inevitably means that the gorillas are excluded from certain areas and forced to live in sub-optimal habitat. For example, although in Zaire the boundary of the Park extends down to $2280 \mathrm{~m}$, in the worst protected area, Mikeno, most of the gorillas were found above $3200 \mathrm{~m}$ and some higher than $3660 \mathrm{~m}$. Disturbance, as well as exclusion to unsuitable high altitude habitat, would be expected to cause a higher mortality amongst immatures than adults, and also a lower reproduction rate due to stress.

As a result of the census it is possible to pinpoint those parts of the conservation area most in need of better protection. These are the Mikeno region of Zaire (where 10 years ago the highest density of gorillas in the Virungas was found), and in Rwanda, southern Karisimbi and Sabinyo. For at least 15 years the southern flanks of Karisimbi volcano have had a very low gorilla population, although the habitat seems ideal for gorillas. Because of its distance from the Park headquarters, this area has always been the most difficult to patrol, and for years poachers and wood/ bamboo cutters have had almost unchallenged

Oryx Vol 18 No 1 
access to the region. With increased protection, there is no reason why this very large area of excellent gorilla habitat would not be gradually repopulated; it could probably support another 50 gorillas.

Uganda's Gorilla Game Sanctuary is by far the worst protected region of the Virunga conservation area. Permanent settlements exist within the Sanctuary which, although it only comprises 8 per cent of the total conservation area, is vital to the survival of gorillas in the eastern Virungas. Without the Sanctuary, the width of the eastern region is halved, becoming a narrow strip of $3 \mathrm{~km}$ by $13 \mathrm{~km}$, bisected by a major smugglers' trail.

There is little doubt that the Mountain Gorilla Project in Rwanda has achieved considerable success in conservation of the Virunga gorillas with its three-pronged approach of protection, tourism development and education. The 1981 census has indicated an improved recruitment rate to the Rwandan population as a result of better protection, and the dramatic increase in tourism has given Rwanda widespread publicity internationally, as well as financial profit for the Park for the first time in its history.

A major problem of protection in the Rwandan Park is that so many people need to enter the Park in search of water. Since the water catchment area was virtually halved in the late 1960s for agricultural development, there has been a water shortage around the Park during the dry seasons. Provision of more underground pipes, as on Visoke volcano, might well ease the problem, and would remove an excuse used by poachers and wood cutters to enter the Park. Wood and bamboo are abundant in plantations around the Park, and meat from poaching is usually sold, rather than being a dietary necessity.

The census has provided no evidence to suggest that so far the regular 'disturbance' of gorilla groups by small parties of tourists has had any effect on the reproductive rate. In fact the proportion of immatures in the three 'tourist' groups at the time of the census was 54 per cent, compared with 49 per cent in four 'research' groups and 39 per cent in five 'unguarded' groups in Rwanda. For this to continue, the temptation to increase the number of daily visitors for gorilla viewing should be resisted; large groups of poorly controlled visitors could easily negate the habituation of the gorillas, and create dissatisfaction, with consequent negative feedback, on the part of the visitors. The danger of habituated gorillas contracting human diseases, such as respiratory infections, will always exist, but can be minimised by avoiding close contact and keeping visitor numbers to a minimum.

Finally, as nearly 60 per cent of the conservation area is in Zaire, it is vital that assistance is given to the Zaire Park authorities if mountain gorillas are going to survive. The Zaire section of the conservation area is generally more difficult to patrol and the guards urgently need equipment. This census has indicated how rapidly increased protection can translate into a reproductively healthier gorilla population. We estimate the carrying capacity of the Virunga conservation area to be between 400 and 480 mountain gorillas. Given the present population composition, both Harcourt et al. (1981) and Weber and Vedder (1983) have suggested that with full protection over the whole area, it is conceivable that the Virunga population could reach these levels by about the year 2000 .

\section{Acknowledgments}

The Governments of Rwanda, Uganda and Zaire, particularly their conservation departments (Office Rwandais du Tourisme et des Parcs Nationaux, Uganda Game and Forest Departments, Institut Zairois pour la Conservation de la Nature) made the work reported here possible. The 1981 census was funded by the World Wildlife Fund, and especially the New York Zoological Society, with additional aid from the African Wildlife Foundation and the Fauna and Flora Preservation Society. It also benefited from the help of J.P. von der Becke, C. Ireland, A. H. Pierce and K.J. Stewart.

\section{References}

Harcourt, A.H. 1981. Can Uganda's gorillas survive?-a survey of the Bwindi Forest Reserve. Biol. Conserv. 19, $269-282$

Harcourt, A.H. and Fossey, D. 1981. The Virunga gorillas: decline of an 'island' population. Afr. J. Ecol. 19, 83-97.

Harcourt, A.H., Fossey, D. and Sabater Pi. J. 1981. Demography of Gorilla gorilla. J. Zool., Lond. 195, 215 233

Schaller, G.B. 1963. The Mountain Gorilla. University of Chicago Press.

Weber, A.W. and Vedder, A. 1983. Population dynamics of the Virunga gorillas: 1959-1978. Biol. Conserv. 26, 341366

C. Aveling, Frankfurt Zoological Society, Alfred-Brehm Platz 16, 6000 Frankfurt am Main 1. West Germany.

A.H. Harcourt, Department of Applied Biology, University of Cambridge, Pembroke Street, Cambridge CB2 3DX, UK. 